\title{
Travellers' preferences towards existing and emerging means of first/last mile transport: a case study for the Almere centrum railway station in the Netherlands
}

\author{
Bas Stam ${ }^{1}$, Niels van Oort ${ }^{2 *}$, , Hilke J. van Strijp-Harms ${ }^{1}$, Stefan C. van der Spek ${ }^{3}$ and Serge P. Hoogendoorn ${ }^{2}$
}

\begin{abstract}
First/last mile transport is essential for transit but is often found to be the weakest link in a trip. Moreover, as a result of multiple developments (e.g. demographic shifts, urbanization, climate change, technology advancement) first/ last mile transport will likely change rapidly. The literature review of this study shows six different categories of factors affecting first/last mile mode choice: (1) traveller, (2) psychological, (3) first/last mile trip, (4) first/last mile modes, (5) built environment, and (6) main stage. We used this framework to understand and predict the complex process of mode choice, specifically given the emerge of new modes. The performed mode choice experiment shows varying results regarding the preferences of travellers for existing and new means of first/last mile transport. Four future scenarios (varying in level of sharing and flexibility of rides) are investigated. Traditional means of transport such as private vehicles and traditional ride services remain preferred over shared vehicles and on-demand ride services. For instance, $21 \%$ of the travellers chooses a private but no shared vehicle, and $12 \%$ chooses a traditional but no ondemand ride service. On the other hand, $21 \%$ of the travellers prefer a shared vehicle and $23 \%$ prefer an on-demand ride service whenever these vehicles/services are available. These results illustrate that when mode choice factors are absent and there are no restrictions taken into account (for example the possession of a car and driving license when choosing car), the actual chosen means of transport in the current situation differs from the preferred means of transport in the future. The results also show potential for new, emerging, means of first/last mile transport. According to the 'preferred situation' by travellers, transit nodes and first/last mile systems require a different design regarding first/last mile facilities, dependent on the scenario(s) that will develop. The challenge for decision makers and planners is to steer mode choice decisions in the direction according to their policy objectives, where our insights support the corresponding design choices and policy interventions.
\end{abstract}

Keywords: First/last mile transport, Mode choice, Preferences, Shared mobility, On-demand rides, Scenario's, Emerging modes

*Correspondence: n.vanoort@tudelft.nl

2 Department of Transport and Planning, Faculty of Civil Engineering and Geosciences, Delft University of Technology, Stevinweg 1, 2600 GA Delft, The Netherlands

Full list of author information is available at the end of the article

\section{Introduction}

Multimodal passenger transportation is gaining more attention with the ongoing climate change discussion and the increasing possibilities to combine existing and new means of transport to travel from A to B. According to PwC [22], five global megatrends are reshaping the world, and their implications will be significant for a broad range of industries, organisations and the wider society, 
(1) demographic and social change, (2) rapid urbanisation, (3) climate change and resource scarcity, (4) technological breakthroughs, and (5) shift in global economic power. The urban transportation sector will face a change in needs and preferences because of among others demographic shifts, urbanization, and climate change. Because of demographic shifts transport options must be expanded to meet multiple needs. Because of urbanization more people are travelling (while many transport services are exceeding capacity already) which requires more efficient transport. Last but certainly not least, climate change asks for environmentally friendly passenger transport. Because of this, there is a need for a more personalized, efficient, and environmentally friendly passenger transport. Public transport seems to be an obvious solution, as it can transport a large number of people at an efficient manner. In addition, public transport brings many other indirect positive effects such as increased access to services and activities. However, public transport has the disadvantage to be dependent on first/last mile transport which are found to be the weakest links in a public transport chain [17].

\subsection{Research question}

This research elaborates on first/last mile transport in further detail and aims to provide insights in the preferences of travellers for existing and new means of first/last mile transport such as shared vehicles and on-demand ride services. The following main research question was formulated:

\section{RQ: What impact do new means of first/last mile transport have on the preference of travellers regard- ing first/last mile transport?}

The outcomes of this research can be used for both scientific and practical purposes. For scientists, additional knowledge helps to understand and make predictions regarding future first/last mile mode choice. Urban planners, municipalities and transport authorities can benefit from the results of this study by taking into account the preferences of travellers when designing transit nodes and first/last mile systems. For example, regarding the number of vehicles that should be provided or amount of space that has to be reserved.

\subsection{Terminology}

With the growing importance of multimodal transport, an increasing number of studies focuses on the first/last mile of the journey. In general, a multimodal trip can be divided into three stages; first mile, main stage, and last mile. The main stage usually describes the stage which covers the largest distance. First/last mile (or access/ egress) describes the direction in which the trip is made. However, when a trip is made for the second time but in the other direction, the first mile becomes the last mile and vice-versa. Specifying the location (e.g. home-end/ activity-end) of the first/last mile trip leads to a consistent usage of the terms at both the origin and destination side (Fig. 1). For mode choice this is important, because usually different means of first/last mile transport are available at the home-end and activity-end of the trip.

\subsection{First/last mile mode choice factors}

Mode choice is an extensively researched topic without one universally applicable definition. De Witte et al. [9] aimed to gain a better understanding of the notion and analysed 76 studies from different research fields that used the term modal choice. The review illustrates that the interpretation of the term modal choice differs per study and depends on the research perspectives and objective as well. Because the researchers found no general definition, they proposed the following definition of modal choice from a multi-disciplinary approach:

\section{'the decision process to choose between different}

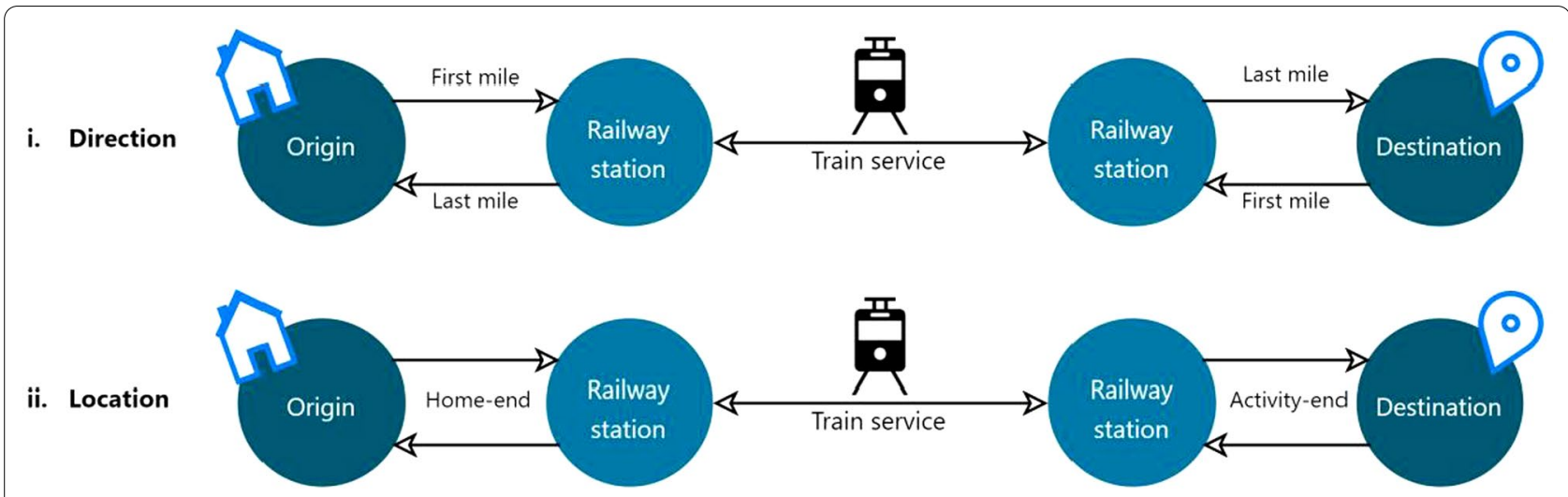

Fig. 1 Trips of a multimodal journey described in terms of (i) direction and (ii) location 
transport alternatives, which is determined by a combination of individual socio-demographic factors and spatial characteristics, and influenced by socio-psychological factors'

First/last mile mode choice is a specific topic within the complex field of (multi-modal) mode choice. Because multimodal trips consist of different stages, multiple mode choice decisions have to be made. The factors that play a role in this process can vary per stage and can therefore differ from the general mode choice determinants $[2,29]$.

Various types of studies have included first/last mile mode choice factors. However, the factors that have been considered in each study strongly depends on the aim of the research as was also concluded by De Witte et al. [9] during their review on mode choice in general.

Instead of researching first/last mile mode choice separately from the main stage, some of the studies combined all trip stages to research the attractiveness of multimodal transport in general $[2,8,17,24,27]$. Studies that do exclude the main stage, mainly research one of the other stages, either the home-end or activity-end. The number of studies that focus on home-end trips are, compared to studies on activity-end trips, found in greater numbers, possibly due to the larger number of options available at the home-end of the trip. For other studies, the distinction between both trip-ends was the motivation to research the differences in factors between both [13].

Besides the trip stages, the considered means of first/ last mile transport and transit nodes are different in each study. Especially studies performed in the Netherlands, mainly focus on the role of the bicycle solely $[21,24,27]$. The bicycle accounts for the largest share of home-end trips (43\%) and is therefore an interesting vehicle to study for researchers in this country [15]. In other countries where the bicycle plays a less prominent role, other means of first/last mile transport have been researched more frequently. Since the bicycle is considered a poor man's vehicle in Indian cities, other transport means such as rickshaws (i.e. human-powered tricycles) have a dominant role [12]. In Vietnam, the motorcycle is extremely popular, also for short distance trips which are attractive to walk [26]. The aim to increase the walking share is a trending topic, also in the United States where short car trips have a predominant role relative to other transport means [5]. Besides studies on existing means of transport, other researchers focus on the potential of emerging means of transport such as demand responsive transport (DRT) and automated vehicles for activity-end trips $[1,29]$.

The variation in researched means of transport per country can also be observed for the type of transit nodes. As mentioned before, the train is used as the main transport mode for the majority of the multimodal trips in the Netherlands. As a result, a large number of studies have focused on railway stations as transit node [10, $11,17,19,21,24,27,29]$. However, studies in other countries, where other means of transport are dominating the main stage of multimodal trips, consider other transit nodes such as bus rapid transit (BRT) stations, light-rail transit (LRT) stations, mass rapid transit (MRT) stations and high-speed rail (HSR) stations [14, 16, 18, 28].

It can be concluded that studies on first/last mile mode choice are diverse regarding the considered trip stages, means of first/last mile transport and transit nodes. Most studies are performed with a specific aim, strongly related to the country in which the research takes place. For example, to stimulate walking or increase the bicycle share.

Based on the factors that were found during the literature review, six distinctive categories were defined to which all first/last mile mode choice factors can be assigned to. These six categories together form the first/ last mile mode choice framework (Fig. 2):

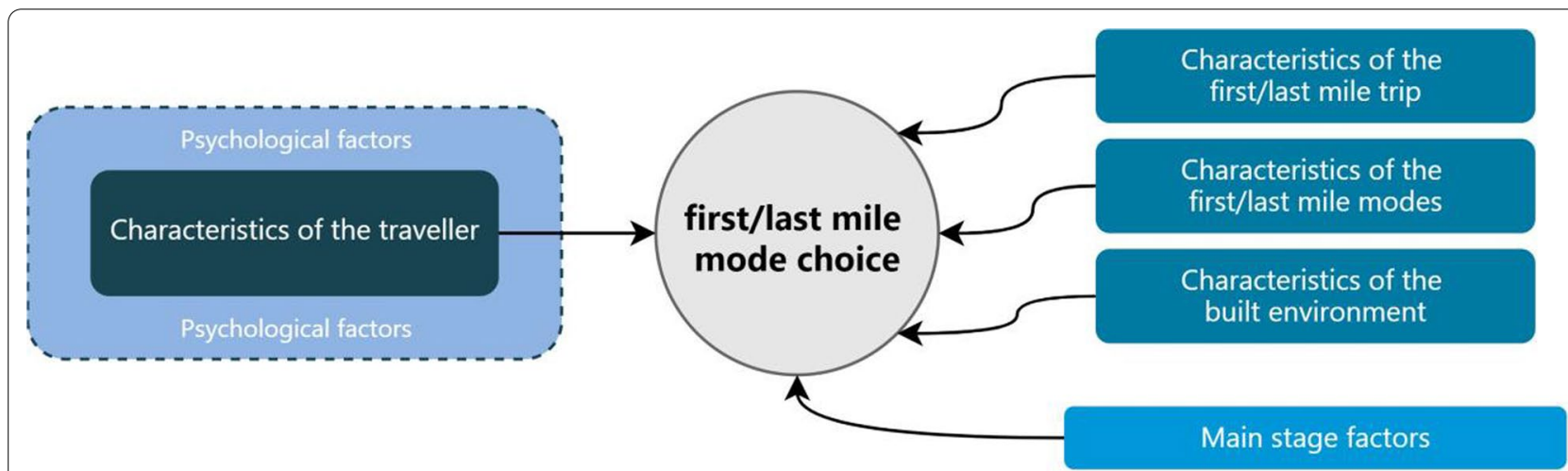

Fig. 2 First/last mile mode choice framework 
1. Characteristics of the traveller

2. Psychological factors

3. Characteristics of the first/last mile trip

4. Characteristics of the first/last mile modes

5. Characteristics of the built environment

6. Main stage factors

The first category, characteristics of the traveller, entails the individuals' personal and household situation. Psychological factors such as attitude, perception, lifestyle and habits are also traveller dependent but reflect unobserved, or latent, variables. These variables either have no measurement scale or are perceived differently per individual. The third category (characteristics of the first/last mile trip) includes all trip specific determinants. The distance, for example, is widely researched but also the trip purpose and the weather conditions can be assigned to this category. First/last mile mode characteristics form the fourth category and only include factors that are related to the means of transport. Travel time and cost are among the most reviewed factors in this category. The fifth category characterises the built environment in which the first/ last mile trip, and thus the mode choice, takes place. Determinants among this category can be classified according to the variables density, diversity and design, also known as the '3Ds' [6]. The sixth and last category includes factors that are related to the main stage and were found to influence the first/last mile mode choice as well. These six categories and all factors that fall within those categories are found to influence first/last mile transport.

\subsection{Outline}

This paper is organized as follows. In the following chapter, the methodology of the research is elaborated on. This chapter describes the construction of scenarios, the location for the case study and the set up of the survey that has been conducted for this research in further detail. In chapter 3 the results are given and discussed. Finally, in chapter 4, conclusions are drawn and discussed, and recommendations are provided.

\section{Research approach}

This chapter describes the research approach that has been followed to collect data on travellers' preferences regarding existing and emerging means of first/last mile transport. First, scenarios were drawn to distinguish future developments paths for first/last mile transport. Hereafter, a location for the case study was selected and finally a survey was set up and conducted.

\subsection{Scenario design}

As a result of multiple trends and developments (e.g. demographic shifts, urbanization, climate change, technology advancement) urban mobility, and therefore first/last mile transport, is likely to change fundamentally.

Many of the novel and innovative means of transport that are emerging can be assigned to the concept called shared mobility. Two categories can be distinguished: the sharing of a vehicle and the sharing of a passenger ride [23]. The principle of the vehicle sharing services is simple, a traveller gains the benefit of a private vehicle without the costs and responsibilities of ownership. This service can be distinguished from the other service which do not share vehicles, but rides. These rides can either be provided by drivers who use their own private vehicle or by taxi or public transport companies. For this research, the following services have been considered: (1) carsharing, (2) bikesharing, (3) e-scooter sharing, (4) individual on-demand ride services, and (5) collective on-demand ride services. The first three services can be assigned to the vehicle sharing concept while the latter two are among the ride sharing one.

The success of the services is expected to be dependent on two main driving forces. On the one hand, the degree to which the vehicle sharing economy develops, and on the other hand, the degree to which ride sharing services are offered. Considering a high and low evolution of both the driving forces, four distinguishable scenarios were constructed based on literature and interviews with experts in the field. In each of the four scenarios different means of first/last mile transport are expected to have a dominant role (Fig. 3). Using this method with four 'extreme' scenarios we were able to capture people's preference and how this changes when specific means of transport are absent.

Scenario 1 illustrates a situation without shared vehicles and on-demand ride services. It is assumed that people remain attached to their private vehicles and public transport is still provided according to traditional fixed routes and timetables. In scenario 2, shared vehicles instead of private vehicles are available. Still, ride services are provided the traditional way as in scenario 1 . Scenario 3 on the other hand, considers a situation in which private vehicles are combined with ride services at an on-demand basis. Examples of the individual form are ridesourcing where drivers use their own private vehicles (e.g. Uber) and e-hailing where the service is provided by a third party or taxi company [7]. For the collective form there is ridesplitting (e.g. UberPOOL) and demand responsive transit (DRT). Different from ridesplitting, drivers of the DRT service are employees of the respective service provider. Scenario 4 illustrates a situation in 


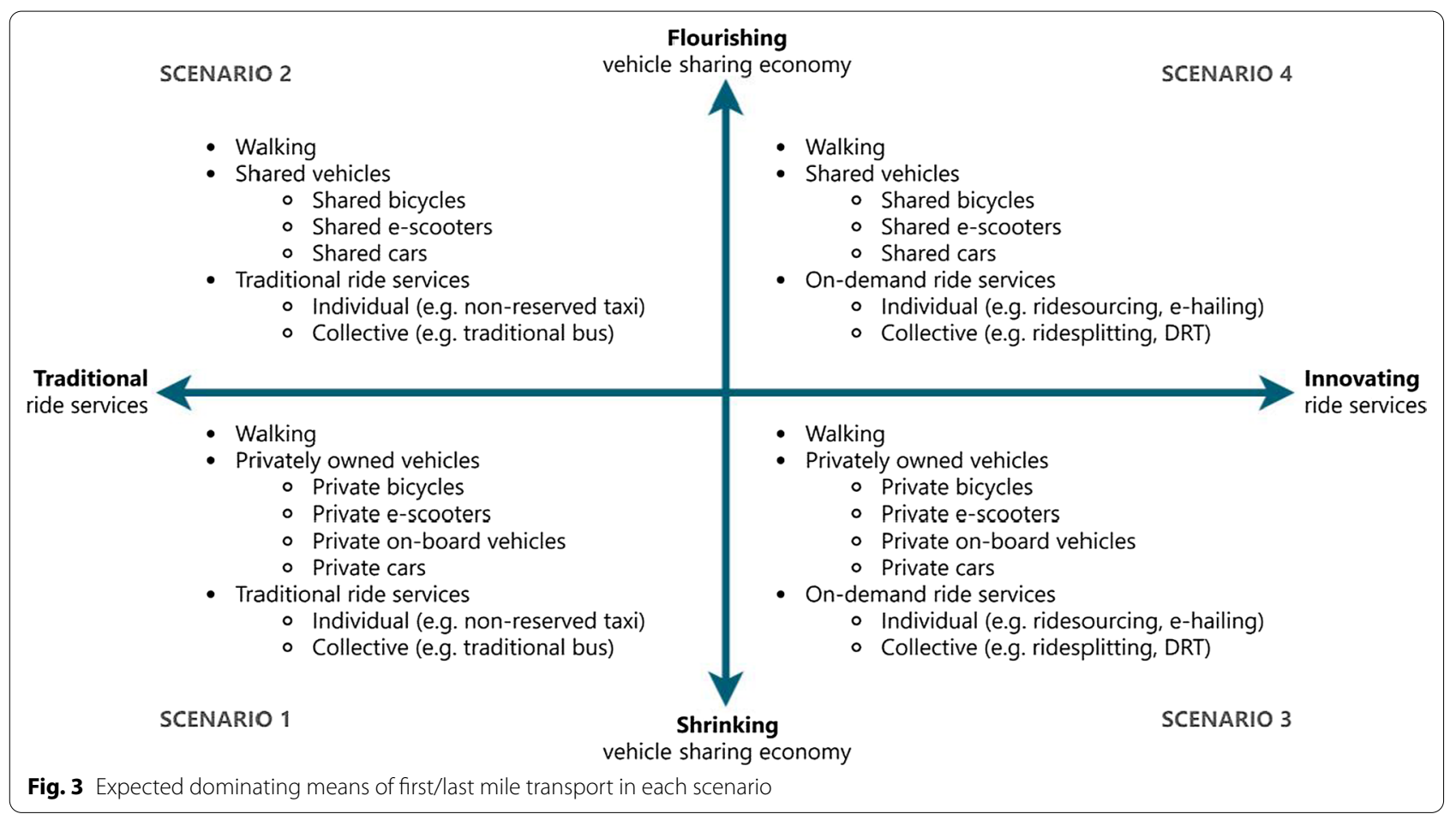

which both shared vehicles and on-demand ride services are available.

The scenarios matrix will later be used in the survey to collect data on travellers' preferences regarding first/last mile mode choice in four different scenarios. Before the survey is constructed, a case study location is selected where the survey will be performed.

\subsection{Case study}

To gain insights into the modal choice decisions of travellers, we performed a case study. One specific railway station is selected to collect this data for the predefined scenarios that are constructed in the previous subparagraph. For this research, the Almere Centrum railway station in the Netherlands was selected as case study location based on various characteristics. Almere is located in the province of Flevoland, half an hour drive from Amsterdam, and has more than 200.000 inhabitants. Almere Centrum is one of the six train stations in Almere, and used by 25,888 travellers on an average weekday, especially during the morning peak (18.2\%) and the evening peak (13.5\%) (NS [20]. Moreover, there is a wide variety of first/last mile facilities and services at Almere Centrum: travellers can make use of a car parking facility and various bicycle parking facilities, there are shared vehicles (car and bicycles) available, there is a Kiss + Ride facility and a taxi stand, and last but not least, there is a bus station where various lines have their stop.
The Almere Centrum railway station is representative of Dutch medium sized stations.

\subsection{Survey}

A mode choice experiment was set up and conducted to observe current and future mode choice decisions. Below, we briefly describe how the survey was designed, implemented and executed.

\subsubsection{Method}

Although an extensive list of factors on first/last mile mode choice was found in our literature review, the survey of this research will not specify attributes. Using attributes and varying with attribute levels would make the research too extensive and does not fit in the available amount of time. Because attributes will be absent, mode choice decisions of respondents are dependent on the available information and expectations regarding the service provided by the different means of first/last mile transport.

Because travellers at railway stations do not have the time to complete a survey on site, the survey was made online. This allows travellers to complete the survey at, for them, a suitable moment. Google Forms was used to construct and conduct the survey. The tool has all the features that are required for this survey, including survey logic and image choice. Survey logic makes it possible to redirect respondents to a specific question based on a 
given answer. Image choice makes it possible to show figures as multiple-choice options instead of text only. The digital survey was made accessible for travellers via a link and QR code, depicted on the flyers that were distributed at Almere Centrum.

\subsubsection{Design}

Because surveys are often experienced as dull, the design of the survey plays a crucial role to get enough and reliable responses. The basic principle for the construction of the survey was to make the survey easy and clear to understand. Besides, respondents should be able to complete the survey within a limited amount of time. Since most of the travellers are familiar with the Dutch language, the survey was designed in Dutch. During the construction process, feedback was asked from various persons with different backgrounds to improve the quality of the survey and to eliminate vagueness and uncertainties. The remainder of this subparagraph briefly explains all parts of the survey.

2.3.2.1 Introduction section of the survey The introduction of the survey describes its background and purpose. The format and the expected amount of time it takes to complete the survey are also communicated. The contact details of the researcher are provided at the end of the introduction to allow respondents to seek contact when they have any questions or comments.

\subsubsection{Part 1: Station function Because first/last mile} mode choice strongly depends on the availability of transport means, the first part of the survey aims to capture the station function of Almere Centrum for each respondent. Besides, respondents are asked to select the date and time on which the trip was made. This information can later be used to identify irregular mode choice decisions in case of extraordinary events (e.g. disrupted transport services, extreme weather conditions). Based on the respondent's answer to the station function, a respondent is redirected to the survey that applies to him or her, which can be either the home-end or activity-end survey. Respondents who do not use the train or those who use the Almere Centrum station to transfer between trains are being thanked for their cooperation but precluded of the remaining questions.

2.3.2.3 Part 2: Current mode choice In the second part of the survey, respondents are asked to specify the means of transport they used for the trip to/from the railway station. Furthermore, respondents are asked to specify the distance of their home-end or activity-end trip. Because the distance was found to influence first/ last mile mode choice by many researchers during the literature review, the factor is included in the survey.

2.3.2.4 Part 3: Future mode choice The third part asks respondents to choose a means of first/last mile transport in each of the four scenarios that were constructed in Sect. 3.1. They are emphatically asked for their preferred future transport means assuming that all modalities and required facilities are available. This also means that respondents without a car and/or driving license can choose for a car, private or shared dependent of the scenario. Each means of first/last mile transport is explained briefly at the beginning of this section. Still, this information is also provided at each question for the means of transport where respondents can choose from. If respondents indicate to prefer a shared vehicle in scenario 2 and/or 4 , an additional question is asked to discover the preferred form of sharing.

2.3.2.5 Part 4: Final questions In the fourth and last part of the survey, respondents are asked to answer four general questions about their gender, age, driver's license possession and trip purpose. All these factors were found to influence first/last mile mode choice during the literature review and are easy to analyse in this survey. Moreover, NS Stations provided data on the populations' age and trip purpose, which allows the researcher to make comparisons. For the other features of which data is missing, other sources will be consulted to make comparisons.

\subsubsection{Practical information}

The survey was conducted in week 47 of 2018 from Monday 19 November until Friday 23 November. During these five days, flyers were distributed among travellers at Almere Centrum during the morning peak (07:00-09:00) and evening peak (16:00-18:00). No extraordinary events (e.g. disrupted transport services, extreme weather conditions) occurred during these days. Although the weather conditions in November are different from other months, general mode choice decisions are expected to be captured by this survey. The surveyor was present during all peak hours on all weekdays. On Tuesday and Friday, an extra surveyor provided assistance. Because multiple entrances and exits are present at railway station Almere Centrum, the surveyor(s) changed location(s) during the week. This also reduced the chance of asking travellers a second time. Because it was not allowed to be active on the platforms or block the transfer of travellers, flyers were distributed at a sufficient distance from the gates, entrances and elevators. Travellers were asked to fill in the survey online via the link on the flyer. 
The minimum number of respondents that is required to get statistically significant results can be calculated with the following equation:

$$
\text { Sample size }=\frac{\frac{\mathrm{z}^{2 *} \mathrm{p}(1-\mathrm{p})}{\mathrm{e}^{2}}}{1+\frac{\mathrm{z}^{2 *} \mathrm{p}(1-\mathrm{p})}{\mathrm{e}^{2} \mathrm{~N}}}=\frac{\frac{1.96^{2} * 0.5 *(1-0.5)}{0.05^{2}}}{1+\frac{1.96^{2} * 0.5 *(1-0.5)}{0.05^{2} * 4,712}}=355
$$

with: $\mathrm{z}=\mathrm{z}$-score $(1.96$ for $95 \%$ confidence level), $\mathrm{p}=$ standard of deviation (percentage in decimal form, $50 \%=0.5$ ), $\mathrm{e}=$ margin of error (percentage in decimal form, $5 \%=0.05$ ), $\mathrm{N}=$ population size (average number of weekday morning peak travellers $=4,712,18.2 \%$ of 25,888 ).

For the majority of the variables (z-score, standard of deviation and margin of error), standard values can be used. However, the population size refers to the number of people that are being researched. For this research, weekday morning peak travellers are among the group of interest. According to the formula for the desired sample size, 355 respondents are required to get statistically significant results.

\section{Results}

In this chapter the results of the mode choice experiment are presented and observations are made in order to give an answer on our research question: 'what impact do new means of first/last mile transport have on the preference of travellers regarding first/last mile transport?'

In total, 1,955 flyers were distributed among travellers at railway station Almere Centrum and 442 surveys were completed at the end of the week. After filtering the outliers, 401 surveys remained useful for further analyses. Because a minimum of 355 respondents was required, it can be concluded that the achieved sample is sufficient to get statistically significant results for the total population of interest.

\subsection{Data analysis}

The collected data from the survey is analysed and compared with data from the total population. For this research, data on gender, age, trip purpose and driver's license possession were collected (Table 1). Regarding the age and trip purpose, NS Stations [20] provided data on the total population which was used for validation purposes. However, it should be mentioned that flyers for the survey of this research were distributed during weekday peak hours only, while NS Stations gathered general data from travellers at Almere Centrum. For the other two factors, other data sources were consulted to validate the data.

The distribution of men and women is 55\% versus $45 \%$ respectively. As mentioned, NS Stations did not provide data on the gender of the respondents.
Table 1 Survey data compared with population data

\begin{tabular}{|c|c|c|c|}
\hline & Survey data & Population data $^{a}$ & \\
\hline \multicolumn{4}{|l|}{ Gender } \\
\hline Men & $55 \%$ & $55 \%$ & $0 \%$ \\
\hline \multirow[t]{2}{*}{ Women } & $45 \%$ & $45 \%$ & $0 \%$ \\
\hline & $100 \%$ & $100 \%$ & \\
\hline \multicolumn{4}{|l|}{ Age } \\
\hline $0-19$ & $11 \%$ & $16 \%$ & $-5 \%$ \\
\hline $20-24$ & $17 \%$ & $24 \%$ & $-7 \%$ \\
\hline $25-44$ & $33 \%$ & $31 \%$ & $+2 \%$ \\
\hline $45-64$ & $36 \%$ & $26 \%$ & $+10 \%$ \\
\hline \multirow[t]{2}{*}{$65+$} & $3 \%$ & $4 \%$ & $+1 \%$ \\
\hline & $100 \%$ & $100 \%$ & \\
\hline \multicolumn{4}{|l|}{ Trip purpose } \\
\hline Commuting/business & $72 \%$ & $54 \%$ & $+18 \%$ \\
\hline School/study & $21 \%$ & $13 \%$ & $+8 \%$ \\
\hline \multirow[t]{2}{*}{ Social/recreation } & $7 \%$ & $33 \%$ & $-26 \%$ \\
\hline & $100 \%$ & $100 \%$ & \\
\hline \multicolumn{4}{|l|}{ Driver's license } \\
\hline Yes & $80 \%$ & $64 \%$ & $+16 \%$ \\
\hline \multirow[t]{2}{*}{ No } & $20 \%$ & $36 \%$ & $-16 \%$ \\
\hline & $100 \%$ & $100 \%$ & \\
\hline
\end{tabular}

a Population data for gender and driver's license is from CBS and for age and trip purpose from NS Stations

However, the open source dataset of the CBS on passenger mobility in 2017, shows the same ratio of men/ women for travellers making a trip by train [3].

Regarding the age of the respondents, it can be observed that more travellers aged 45-64 are among the respondents of this survey than of NS Stations' $36 \%$ versus $26 \%$ ). The age category $20-24$ on the other hand, is underrepresented (17\% versus $24 \%$ ). Differences for other age categories are within a range of $5 \%$. Because the data from NS Stations originates from surveys as well, it is not sure that values collected via the survey in this research are wrong. Differences can be a result of the time of day at which age cohorts travel because flyers to access the survey were distributed during peak hours only.

The trip purpose was also researched in both the survey of this research and by NS Stations. Differences can be observed for the three distinguished travel motives: (1) commuting/business, (2) school/study, and (3) social/ recreation. Because flyers for the survey were distributed during weekday peak hours, respondents travelling for commuting/business ( $72 \%$ versus $54 \%$ ) and school/study (21\% versus $13 \%$ ) purposes are overrepresented. People travelling for social/recreational purposes are expected to use the railway station especially outside the peak hours and during the weekends. This also explains the lower 
share found in this research (7\%), relative to the value found by NS Stations (33\%).

Of all respondents that completed the survey for this research, $80 \%$ indicated to be in possession of a drivers' license. As for gender, NS Stations did not provide data on this factor. General data on the total number of drivers licenses in the Netherlands, together with the total number of inhabitants, indicate that $64 \%$ of the people are in possession of a driver's license [4]. The high share found in this research illustrates that the possession of a driver's license does not by definition means that this group prefers a car instead of the train.

In general, it can be concluded that the collected sample represents the total population of interest sufficiently for the purpose of this study.

\subsection{Mode choice results}

Data on the current mode choice of travellers was also collected by the survey and the results are visualized in Fig. 4. The current modal split of home-end trips (58\%) shows large shares for the bus (43\%) and the bicycle (41\%). For activity-end trips (42\%), these modes are only used by respectively $18 \%$ and $10 \%$ of the travellers, after walking (67\%). In line with these findings, the majority of activity-end trips (54\%) are of $1 \mathrm{~km}$ or less (Table 2). The distance of home-end trips is on average a little longer, $64 \%$ of the trips are within a range of $1-5 \mathrm{~km}$.

For both home-end and activity-end trips and all four scenarios that were discussed in Sect. 3.1, Sankey diagrams were constructed based on the outcomes of the survey. In respectively Figs. 5 and 6 the Sankey diagrams for home-end trips and activity-end trips are presented. The left side of the diagrams show the current means of first/last mile transport, while the right side represents
Table 2 Distance of home-end and activity-end trips to/from Almere Centrum

\begin{tabular}{lll}
\hline Home-end trips (\%) & Trip distance & $\begin{array}{l}\text { Activity- } \\
\text { end trips } \\
\text { (\%) }\end{array}$ \\
\hline 12 & $<1 \mathrm{~km}$ & 54 \\
64 & $1-5 \mathrm{~km}$ & 34 \\
16 & $5-0 \mathrm{~km}$ & 9 \\
6 & $>10 \mathrm{~km}$ & 1 \\
2 & I don't know & 2 \\
\hline
\end{tabular}

the chosen means of transport in the considered scenario. Because no attributes were specified in the survey, the observed mode choice in each scenario represents the preferred transport means of travellers. The remainder of this chapter presents the most important observations for home-end trips, activity-end trips and first/last mile trips in general.

\subsubsection{Home-end trips}

Figure 5 shows the expected modal shift for homeend trips in each of the four scenarios. It was already observed that in the current situation, the majority of the home-end trips are made by bicycle (41\%) and bus (43\%). In scenarios where these services are not available, the preference of travellers is divided over all means of first/ last mile transport available. Some interesting observations for home-end trips solely are further discussed underneath the figure.

First of all, the car is found to be a popular transport mode in each of the four future scenarios, regardless of the type of car available (private or shared). Although the car is currently used for only $5 \%$ of the home-end trips
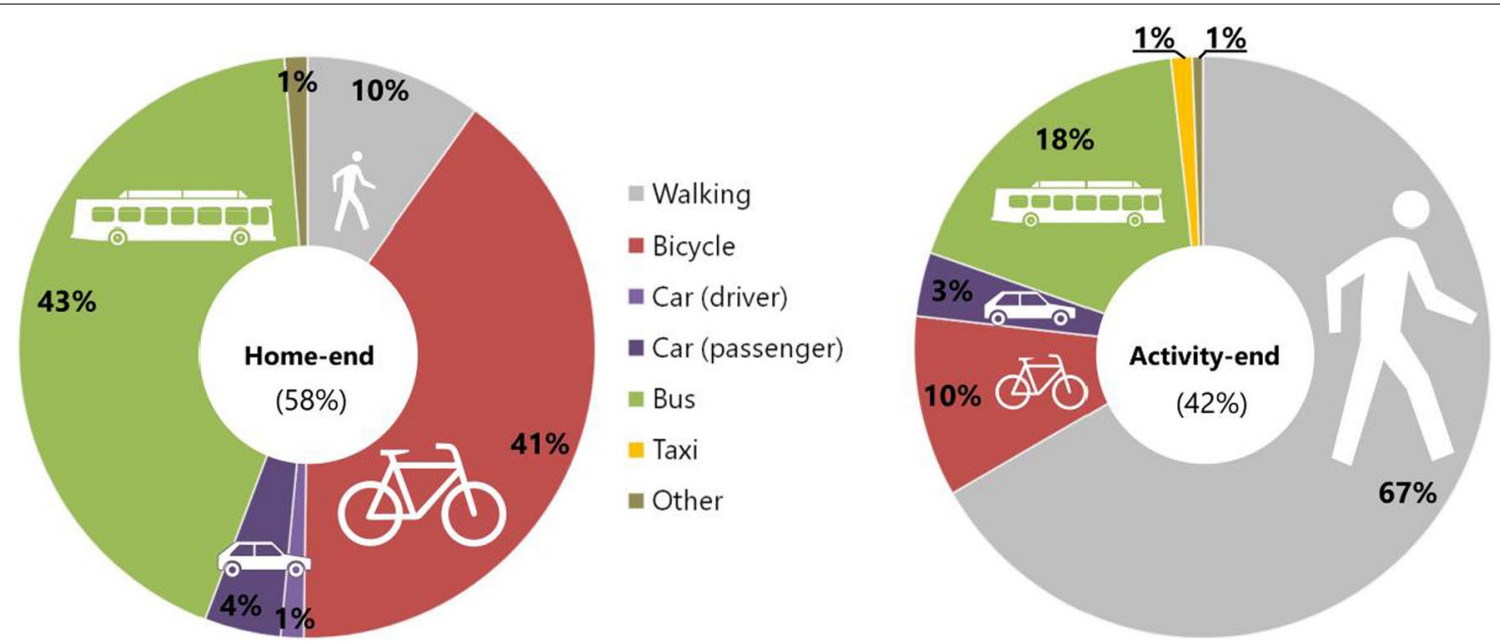

Fig. 4 Modal split of Almere Centrum for home-end trips and activity-end trips 


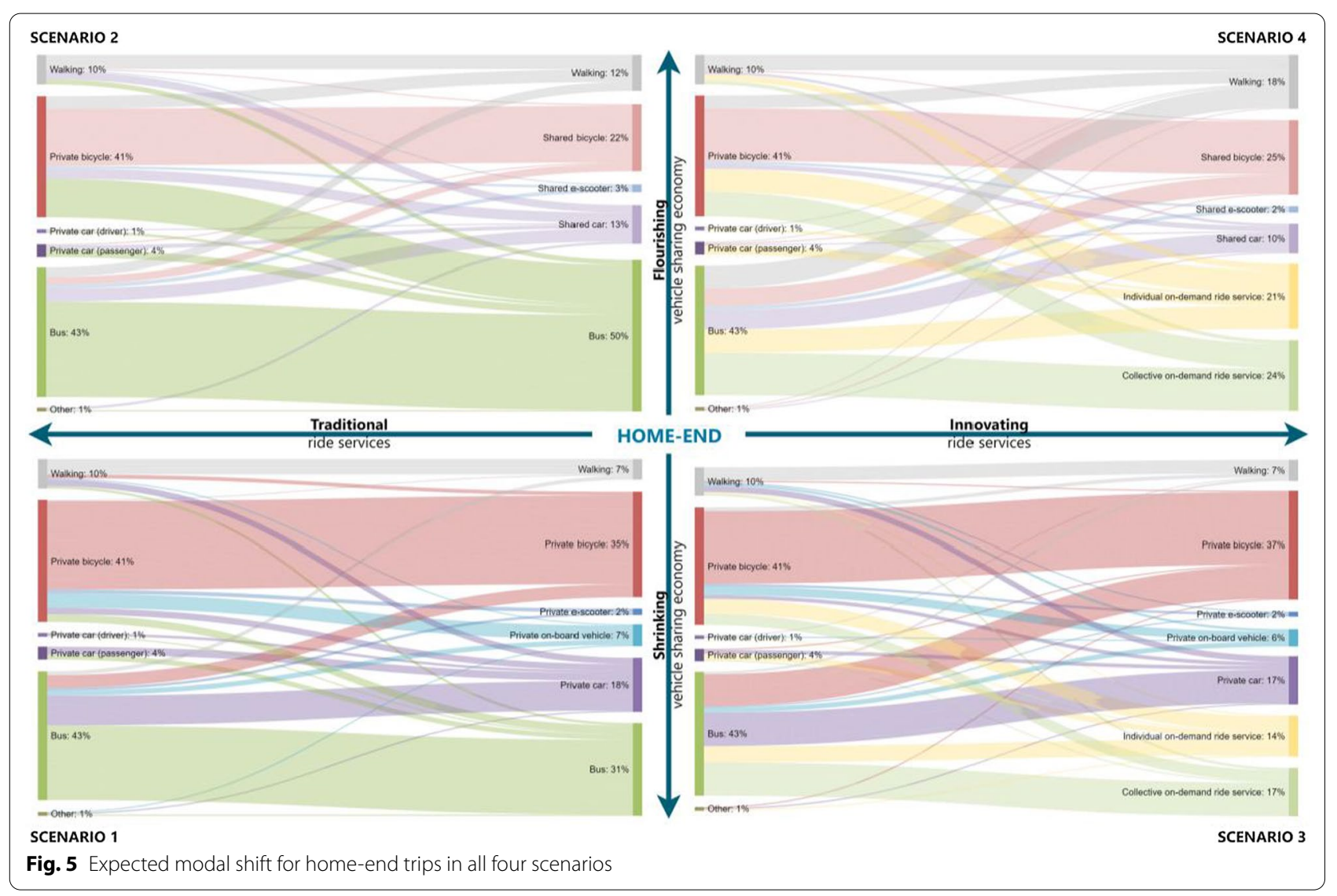

(driver + passenger), the car share in each of the four scenarios is $18 \%, 13 \%, 17 \%$ and $10 \%$ respectively. This means that travellers currently do not use the car or do not have a car or driver's license while they prefer to travel by car to the railway station in the future assuming that the required facilities are available. The data reveals that $32 \%$ of the home-end travellers, which equals 74 respondents, prefer to use the car in one or more scenarios. The numbers illustrate that especially younger $(0-24,57 \%)$ women (62\%) travelling for school/study purposes (51\%) prefer to use a car in at least one of the scenarios. As expected, the home-end distances are larger for this group than for the average home-end traveller. More trips with a length of $5-10 \mathrm{~km}$ and longer than $10 \mathrm{~km}$ are represented in this dataset. Still remarkable is the relatively high share of trips by car which are shorter than $1 \mathrm{~km}(9 \%)$.

Another interesting observation regarding the popularity of the car is found when analysing the characteristics of travellers who choose a private car when available (scenario 1 and 3). Among this group, the percentage of women $(72 \%)$ is even higher than observed during the previously discussed observation. Travellers aged 0-24 account for almost three quarters (72\%) of this group, while the average is $27 \%$. In line with this result, the number of travellers without a driver's license is also higher and accounts for $40 \%$, which is $20 \%$ higher than the average. This illustrates the inexperience of driving a car among a group who prefers to use one.

Both observations show the preference towards the car for specific users of which an explanation is hard to give. Teenagers who do not work yet might get enthusiastic about the idea of travelling by car in the future. However, this does not explain the high share of women among travellers who prefer a car.

The traditional bus remains a popular means of transport in the scenarios where the service is available. In scenario 1 and 2, respectively $31 \%$ and $50 \%$ of the travellers have a preference for the bus. Additionally, a quarter of the travellers (57 respondents) prefer the bus in both of the scenarios. $82 \%$ of this group, already uses the bus in the current situation. Data on the characteristics of these travellers do not show extreme differences regarding the average home-end traveller. Still, a majority of them travels for commuting/business purposes $(81 \%)$ and falls within the age range of $25-44$ and 45-64 (both 39\%). 


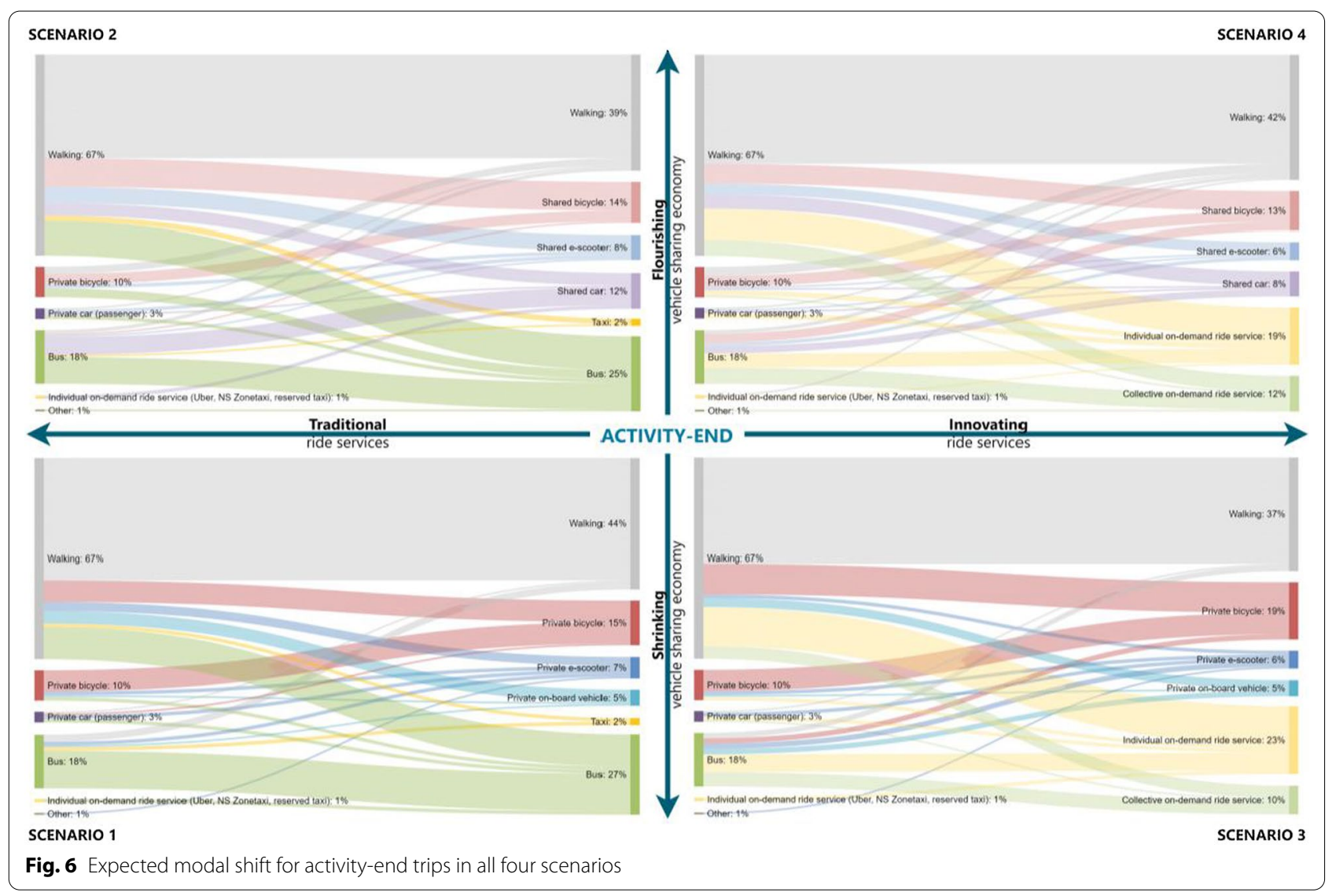

\subsubsection{Activity-end trips}

Figure 6 shows the Sankey diagram for activity-end trips in each of the four scenario's. In general, it can be observed that walking remains a high share among activity-end travellers. However, in each scenario, the share decreases considerably. Some interesting observations for activity-end trips solely are further discussed below.

The share of travellers that walk at the activity-end of the trip reduces in each of the four scenarios $(44 \%, 39 \%$, $37 \%$ and $42 \%$ ) relative to the current situation. The data illustrates that although $67 \%$ of the activity-end trips are made by foot, $20 \%$ of the travellers actually never prefer to walk. This group of travellers prefer not to walk although $82 \%$ of them has to walk less than $1 \mathrm{~km}$. The characteristics of the travellers among this group are not considerably different from the average activity-end traveller.

Besides the group of travellers who never prefer to walk, there is a large share of activity-end travellers (30\%) who indicate to have a preference for walking in each of the four scenarios. Most of them (94\%) do already travel by foot in the current situation. Again, the majority of the trips $(71 \%)$ are less than $1 \mathrm{~km}$. However, $27 \%$ of this group walks a distance of $1-5 \mathrm{~km}$. Characteristic differences are present among this group relative to the average activityend traveller. The share of men among this group is $65 \%$ and also travellers aged $25-44(45 \%)$ are present in larger numbers. This illustrates that middle-aged men travelling for commuting/business purposes $(86 \%)$ are more willing to walk, regardless of the available transport modes and services.

\subsubsection{First/last mile trips in general}

In addition to the home-end and activity-end observations, general observations are done. For these observations, both the datasets of home-end trips and activity-end trips are combined. Especially interesting are the new transport modes and services that are included in the scenarios and the characteristics of travellers who are willing to make use of them. Because the number of travellers with a preference for e-scooter and on-board vehicles was relatively low, merging both datasets also provided a more extensive dataset to analyse.

$21 \%$ of the travellers prefer a shared vehicle when available (in both scenario 2 and 4 ). The results show that slightly more men $(58 \%)$ than women $(42 \%)$ are among this group relative to the average traveller ( $45 \%$ women, Table 1). Another interesting observation is the increased 
share of travellers aged 25-44 (35\%) and 45-64 (40\%). Regarding the trip purpose, $78 \%$ of the travellers in this group indicate to travel for business/commuting purposes. The preference of travellers towards different sharing forms is equally divided.

$21 \%$ of the travellers prefer a private vehicle, but no shared vehicle. To analyse this in further detail, the characteristics of travellers who prefer a private vehicle in scenario 1 , but subsequently no shared vehicle in scenario 2 , are examined. Among the group who do not prefer to share a vehicle, the majority of the travellers are women $(52 \%)$. In line with the unexpected findings on the previous theme, the share of younger travellers aged $0-19$ increased by $5 \%$ to a total of $16 \%$. Looking at the trip purpose of the travellers among this group shows larger shares for school/study (25\%) and social/recreation (12\%) trips.

$23 \%$ of the travellers prefer a flexible ride service when available (in both scenario 3 and 4). On-demand ride services, both individual and collective, can be seen as a flexible upgrade compared to traditional forms such as the bus. Again, it is interesting to see that older people are more willing to make use of innovative services. The share of travellers aged $45-64$ increases by $13 \%$ to a total share of $49 \%$, at the expense of groups aged 20-24 (-5\%) and $25-44(-10 \%)$. An explanation for this can be the accessibility of the bus, which is perceived differently between elderly and youngsters. An on-demand ride service no longer has the issues of accessibility.

$12 \%$ of the travellers prefer a traditional ride service, but no flexible ride service. Travellers who prefer a traditional ride service in scenario 1 , but subsequently no on-demand ride service in scenario 3 are examined. Again, the majority of the travellers (74\%) already travels by bus in the current situation. The characteristics of these travellers show that especially teenagers aged $20-24(30 \%,+13 \%)$ travelling for school/study purposes $(36 \%,+15 \%)$ are among this group.

$10 \%$ of the travellers prefer to use a vehicle that is allowed to be taken on-board in at least one of the scenarios. This option was found popular among current cyclists (38\%), who probably already bring their vehicle on-board, in the form of a foldable bicycle. This specific type of bicycle was not part of the answer options, and existing users are categorised as general cyclists. The data shows that especially travellers aged $25-44(43 \%,+9 \%)$, travelling for commuting/business purposes $(78 \%,+5 \%)$, are among this group. scenarios.

$8 \%$ of the travellers prefer to use an e-scooter in at least one scenario. Again travellers aged $25-44(45 \%,+12 \%)$, travelling for commuting/business purposes $(79 \%,+6 \%)$, are largely represented. Relative to the average traveller (45\% women, Table 1), more women (48\%) are found to be interested in using an e-scooter in at least one scenario. Another interesting observation is the first/last mile distance of e-scooter fans. Especially trips between 5-10 km (27\%, +14\%) are popular among e-scooter fans compared to the average traveller (Table 2), while trips between $1-5 \mathrm{~km}(33 \%,-19 \%)$ are less represented. Still, it should be taken into account that only $8 \%$ of all travellers indicate to use an e-scooter in at least one scenario, which is relatively low.

With the results and observations presented in this chapter, our research question is answered: 'what impact do new means of first/last mile transport have on the preference of travellers regarding first/last mile transport?'

The answer is of course dependent on the scenario that will develop. In this study we distinguished two main driving forces on which the four scenarios were built. On the one hand, the degree to which the vehicle sharing economy develops, and on the other hand, the degree to which ride sharing services are offered.

When shared vehicles (scenario 2 and 4) would replace all private vehicles (scenario 1 and 3 ), it is expected that some of the travellers will start using other forms of traditional transport such as the bus (home-end, scenario 2) and to a lesser extent walking. For home-end trips in particular, it can be seen that the share of bicycles decreases significantly when only shared vehicles are offered. For activity-end trips this trend is much less visible. Compared to the current situation, the bicycle share is even increasing. This most likely has to do with the availability of the availability of this means of transport at the activity end of the trip in the current situation. For e-scooters the difference in private and shared vehicles is barely visible.

When flexible ride services (scenario 3 and 4) would replace all traditional ride services (scenario 1 and 2), the same observation is visible as when the vehicle sharing economy develops. Travellers shift to traditional transport means such as the private bicycle although to a lesser extent. The flexible ride services are most popular among current bus users but also travellers who currently travel by private bicycle (home-end) or who walk (activity-end) shift to this flexible service.

\section{Conclusions, discussion and recommendations}

\subsection{Conclusions}

Because relatively little is known about first/last mile transport in the era of new means of transport, this research aimed to elaborate on the topic in further detail and provided insights in the preferences of travellers for existing and new means of first/last mile transport.

The literature review illustrated that many factors together constitute the choice of a traveller for a specific mean of transport. The mode choice framework that was 
developed distinguished six categories to which all type of first/last mile mode choice factors can be assigned to.

According to the outcomes of this survey travellers have different preferences which do not align with the means of transport that they currently use. Although the car is usually undesired in urban regions, the survey illustrated that many travellers have a preference for the car. Also, traditional transport means such as the private bicycle and the traditional bus are in favour compared to shared vehicles and on-demand ride services. We found that $21 \%$ of the travellers prefer a private vehicle but in scenarios where these vehicles are absent, shared vehicles are not chosen which means that people choose a completely differ means of transport such as walking or ride services. This is also visible for ride services, but to a lesser extent. Here, $12 \%$ of the travellers who prefer a traditional ride service do not choose an on-demand ride when the traditional ones are not available. On the other hand, still $21 \%$ of the travellers prefer a shared vehicle whenever available. In line with this result, $23 \%$ of the travellers prefer an on-demand ride service if available. It should be mentioned that factors (like cost and time) were not taken into account in the mode choice experiment and that the results therefore illustrate a preferred situation. Moreover, travellers were asked to their preferred transport means in the future assuming that all modalities and required facilities are available. This also means that respondents without a car and/or driving license can choose for a car, private or shared dependent of the scenario. When mode choice factors and limitations such as having a car and driving's license to choose the car are taken into account, the actual chosen means of transport in the current situation differs from the preferred means of transport in the future. In this study, where mode choice factors are absent, the results illustrate that there is a potential for the new, emerging, means of first/last mile transport that have been considered in this research. The 'preferred situation' by travellers would mean that transit nodes require a completely different design regarding the first/last mile facilities in each considered scenario.

For urban planners, authorities and operators, it is important to consider which means of first/last mile transport to/from a specific railway station are matching best with policy and societal goals. For Almere Centrum the outcomes showed that more people wanted to travel by car (not taking into account mode choice factors and other factors such as car ownership and driver's license). Designing transit nodes according to the preference of travellers would result in large car parking facilities in each of the four scenarios. However, it is questionable whether car use to/from railway stations should be stimulated, especially when the railway station is located in the city centre. In these areas space is scarce, and cars were found to be the most inefficient means of first/ last mile transport regarding land use. However, first/ last mile mode choice can be controlled for by various factors as was observed for Almere Centrum. The challenge for decision makers and planners is to steer mode choice decisions in the direction according to their policy objectives.

\subsection{Discussion and recommendations}

The results and conclusions that originated from this research are dependent on various assumptions and choices that have been made throughout the process. First of all, of all trends and developments that are expected to influence first/last mile transport in the future, services originating from the shared mobility concept were considered only. Consequently, this research provided a single-concept vision on the future of urban mobility. Future research on other trends and developments is required to understand and predict how the first/last mile sector evolves in the coming years and what the consequences are for transit nodes.

Second, because this research focused on first/last mile trips to/from railway stations in the Netherlands, specific means of first/last mile transport were considered for the construction of the scenarios and survey. For other countries and other transit nodes with different characteristics, other means of first/last mile transport are expected to be relevant and should be included. Although the context differ (e.g. high level bicycle users in the Netherlands), the observations that are made regarding the use of existing and preference for new means of first/last mile transport are relevant for other countries as well. Future research can apply the method that has been followed in this research to gather knowledge on this topic for other nodes and countries. Additionally, the mode choice experiment was performed for Almere Centrum specifically. These outcomes are expected to be especially relevant for transit nodes with similar characteristics. Because the experiment researched the preference of travellers, future research is required for more accurate predictions regarding the first/last mile mode choice of travellers in the future by including first/last mile mode choice factors and attribute levels. The framework that was developed in this research provides information on the factors that can be used.

Last, this research showed that there is potential for new, emerging, means of first/last mile transport. Transit nodes and first/last mile systems will therefore require a different design regarding first/last mile facilities. This research also showed that first/last mile mode choice can be controlled for by various factors. It is recommended to steer mode choice decisions to match the policy goals by 


\section{(re)design first/last mile facilities and apply policy inter- ventions accordingly.}

\section{Acknowledgements}

This research was made possible due to the support of Witteveen+Bos and the TU Delft Smart PT Lab. We thank NS Stations for their data and cooperation which made it possible to distribute flyers at Almere Centrum to collect research specific data. This paper is based on a MSc thesis at Delft University of Technology [25]: http://resolver.tudelft.nl/uuid:5fd1 c404-61 c3-4808-99ac08ac3240781 b. A brief summary of the thesis was presented at the Dutch CVS conference.

\section{Authors' contributions}

The authors confirm contribution to the paper as follows: study conception and design: BS, HJVS-H, SCVS, NVO, SPH; data collection: BS; analysis and interpretation of results: $\mathrm{BS}$; draft manuscript preparation: BS, NVO. All authors reviewed the results and approved the final version of the manuscript.

\section{Funding}

None.

\section{Availability of data and materials}

Not applicable.

\section{Declarations}

\section{Competing interests}

The authors declare that they have competing interests.

\begin{abstract}
Author details
'Witteveen+Bos, Hoogoorddreef 15-2, 1100 AE Amsterdam, The Netherlands. ${ }^{2}$ Department of Transport and Planning, Faculty of Civil Engineering and Geosciences, Delft University of Technology, Stevinweg 1, 2600 GA Delft, The Netherlands. ${ }^{3}$ Department of Urbanism, Faculty of Architecture, Delft University of Technology, Julianalaan 134, 2628 BL Delft, The Netherlands.
\end{abstract}

Received: 18 February 2021 Accepted: 28 September 2021

Published online: 30 October 2021

\section{References}

1. Alonso-González, M. J., Liu, T., Cats, O., Van Oort, N., \& Hoogendoorn, S. (2018). The potential of demand responsive transport as a complement to public transport: An assessment framework and an empirical evaluation. Transportation Research Record. https://doi.org/10.1177/ 0361198118790842

2. Arentze, T. A., \& Molin, E. J. E. (2013). Travelers' preferences in multimodal networks: Design and results of a comprehensive series of choice experiments. Transportation Research Part A: Policy and Practice, 58, 15-28. https://doi.org/10.1016/j.tra.2013.10.005

3. Centraal Bureau voor de Statistiek. (2018a). Personenmobiliteit in Nederland; persoonskenmerken en vervoerwijzen, regio. Retrieved 11-12-2018 https://opendata.cbs.nl/statline/\#/CBS/nl/dataset/83499 NED/table?ts $=1544532869801$

4. Centraal Bureau voor de Statistiek. (2018b). Trends in Nederland 2018. Retrieved from https://www.cbs.nl/nl-nl/publicatie/2018/26/trends-innederland-2018.

5. Cervero, R. (2001). Walk-and-ride: Factors influencing pedestrian access to transit (Vol. 3).

6. Cervero, R., \& Kockelman, K. (1997). Travel demand and the 3Ds: Density, diversity, and design. Transportation Research Part D: Transport and Environment, 2(3), 199-219. https://doi.org/10.1016/S1361-9209(97) 00009-6

7. Coutinho, F. M., van Oort, N., Christoforou, Z., Alonso-González, M. J., Cats, O., \& Hoogendoorn, S.(2020). Impacts of replacing a fixed public transport line by a demand responsive transport system: Case study of a rural area in Amsterdam, Research in Transportation Economics, art. no. 100910

8. Creemers, L., Bellemans, T., Janssens, D., Wets, G., \& Cools, M. (2014). Analyzing access, egress, and main transport mode of public transit journeys: evidence from the Flemish national household travel survey.

9. De Witte, A., Hollevoet, J., Dobruszkes, F., Hubert, M., \& Macharis, C. (2013). Linking modal choice to motility: A comprehensive review. Transportation Research Part A: Policy and Practice, 49, 329-341. https:// doi.org/10.1016/j.tra.2013.01.009

10. Debrezion, G., Pels, E., \& Rietveld, P. (2009). Modelling the joint access mode and railway station choice. Transportation Research Part E: Logistics and Transportation Review, 45(1), 270-283. https://doi.org/10.1016/j. tre.2008.07.001

11. Givoni, M., \& Rietveld, P. (2007). The access journey to the railway station and its role in passengers' satisfaction with rail travel. Transport Policy, 14(5), 357-365. https://doi.org/10.1016/j.tranpol.2007.04.004

12. Goel, R., \& Tiwari, G. (2016). Access-egress and other travel characteristics of metro users in Delhi and its satellite cities. IATSS Research, 39(2), 164-172. https://doi.org/10.1016/j.iatssr.2015.10.001

13. Halldórsdóttir, K., Nielsen, O. A., \& Prato, C. G. (2017). Home-end and activity-end preferences for access to and egress from train stations in the Copenhagen region. International Journal of Sustainable Transportation, 11(10), 776-786. https://doi.org/10.1080/15568318.2017.1317888

14. Jiang, Y., Christopher Zegras, P., \& Mehndiratta, S. (2012). Walk the line: Station context, corridor type and bus rapid transit walk access in Jinan, China. Journal of Transport Geography, 20(1), 1-14. https://doi. org/10.1016/j.jtrangeo.2011.09.007

15. Kennisinstituut voor Mobiliteitsbeleid. (2017). Mobiliteitsbeeld 2017. Retrieved from https://www.kimnet.nl/mobiliteitsbeeld.

16. Kim, S., Ulfarsson, G. F., \& Todd Hennessy, J. (2007). Analysis of light rail rider travel behavior: Impacts of individual, built environment, and crime characteristics on transit access. Transportation Research Part A: Policy and Practice, 41(6), 511-522. https://doi.org/10.1016/j.tra.2006.11. 001

17. Krygsman, S., Dijst, M., \& Arentze, T. (2004). Multimodal public transport: An analysis of travel time elements and the interconnectivity ratio. Transport Policy, 11(3), 265-275. https://doi.org/10.1016/j.tranpol. 2003.12.001

18. Mo, B., Shen, Y., \& Zhao, J. (2018). Impact of built environment on firstand last-mile travel mode choice.

19. Molin, E. J. E., \& Timmermans, H. J. P. (2010). Context dependent stated choice experiments: The case of Train Egress mode choice. Journal of Choice Modelling, 3(3), 39-56. https://doi.org/10.1016/S1755-5345(13) 70013-7

20. NS Stations (2018, 7 November 2018). [Station Almere Centrum: data].

21. Puello, L. L., \& Geurs, K. (2015). Modelling observed and unobserved factors in cycling to railway stations: Application to transit-orienteddevelopments in the Netherlands. European Journal of Transport and Infrastructure Research, 15(1), 27-50.

22. PwC. (2018). Megatrends: 5 global shifts changing the way we live and do business. Retrieved from https://www.pwc.co.uk/issues/megat rends.html.

23. Shaheen, S., \& Chan, N. (2016). Mobility and the sharing economy: Potential to facilitate the first-and last-mile public transit connections (Vol. 42).

24. Shelat, S., Huisman, R., \& Van Oort, N. (2018). Analysing the trip and user characteristics of the combined bicycle and transit mode. Research in Transportation Economics. https://doi.org/10.1016/j.retrec.2018.07.017

25. Stam, B. (2019). Access/egress facilities at railway stations. An exploratory study on the future development of railway station areas. (MSc Thesis), Delft University of Technology, Delft. http://resolver.tudelft.nl/uuid: 5fd1c404-61c3-4808-99ac-08ac3240781b.

26. Tran, M. T., Zhang, J., \& Fujiwara, A. (2014). Can we reduce the access by motorcycles to mass transit systems in future Hanoi? Procedia Social and Behavioral Sciences, 138, 623-631. https://doi.org/10.1016/j.sbspro. 2014.07.248

27. Van Mil, J. F. P. Leferink, T. S., Annema, J. A, et al. (2020). Insights into factors affecting the combined bicycle-transit mode. Public Transport. https://doi.org/10.1007/s12469-020-00240-2

28. Wen, C.-H., Wang, W.-C., \& Fu, C. (2012). Latent class nested logit model for analyzing high-speed rail access mode choice. Transportation 
Research Part E: Logistics and Transportation Review, 48(2), 545-554 https://doi.org/10.1016/j.tre.2011.09.002

29. Yap, M. D., Correia, G., \& Van Arem, B. (2016). Preferences of travellers for using automated vehicles as last mile public transport of multimodal train trips. Transportation Research Part A: Policy and Practice, 94, 1-16. https://doi.org/10.1016/j.tra.2016.09.003

\section{Publisher's Note}

Springer Nature remains neutral with regard to jurisdictional claims in published maps and institutional affiliations.
Submit your manuscript to a SpringerOpen ${ }^{0}$ journal and benefit from:

- Convenient online submission

- Rigorous peer review

- Open access: articles freely available online

- High visibility within the field

- Retaining the copyright to your article

Submit your next manuscript at $\boldsymbol{\nabla}$ springeropen.com 